


\title{
LAS BURBUJAS EN LA CRISIS FINANCIERA
}

\author{
Autor: Ignacio Cervera Conte. ${ }^{1}$ \\ Departamento de Gestión Financiera. \\ Universidad Pontificia Comillas.
}

\section{Resumen}

Todo sistema financiero está al servicio de una economía productiva sostenible en el tiempo. Cuando esto no ocurre, aparecen las burbujas. Una burbuja aparece cuando unas exageradas expectativas conducen a una valoración de los activos por encima de sus valores fundamentales. Este artículo tiene como objetivo la descripción de las principales burbujas que han tenido lugar durante la última crisis para una toma de conciencia de sus efectos perjudiciales para la sociedad. El efecto negativo que tienen sus estallidos hace necesario que el regulador tome medidas preventivas para evitar futuras burbujas. Aquí se sugieren algunas de esas medidas.

Palabras claves: Burbuja Financiera; Sistema Financiero; Crédito; Valoración de Activos Financieros.

\footnotetext{
${ }^{1}$ icervera@cee.upcomillas.es
} 
Bubbles in the financial crisis.

\begin{abstract}
The entire financial system is at the service of a sustainable productive economy over time. When this does not occur, bubbles arise. The term "bubble" refers to a situation in which excessive future expectations cause asset prices to rise far above their fundamentals. The goal of this article is describe the bubbles that led to the current financial crisis in order to raise awareness of their negative effects on society. The negative effects of their outbursts require from the central bank to take measures to avoid bubbles in the future. Some of these measures are suggested in this article.
\end{abstract}

Key words: Financial Bubble; Financial System; Credit; Valuation of Financial Assets.

Recibido: 13-01-2014

Aceptado: 17-03-2014

\title{
1. INTRODUCCIÓN: A VUELTASCONLASBURBUJAS FINANCIERAS E INMOBILIARIAS.
}

Las burbujas financieras e inmobiliarias han sido un tema muy debatido en casi todas las crisis: algunos niegan que existan y otros demuestran con cifras la presencia de estas burbujas a lo largo de la historia pasada y reciente. Cuando todavía se dejan sentir los efectos de la crisis económica y financiera que estalló en los años 2007-2008, las burbujas vuelven a cobrar un cierto protagonismo en los debates económicos que están teniendo lugar en los últimos meses acerca de las políticas monetarias que están llevando a cabo los bancos centrales de las principales economías del mundo. Estos debates se centran concretamente en el papel dela Reserva Federal norteamericana con su Quantitative Easing (programa de estímulos dirigidos a la economía mediante la compra de bonos emitidos por el Tesoro) y con su anunciado Tapering (programa de retirada paulatina de dichos estímulos) al observar signos de recuperación.

¿Estamos ante nuevas burbujas?, se preguntan los expertos. Para algunos como Warren Buffett (principal accionista del holding Berkshire Hathaway) o Janet Yellen (recién elegida presidenta de la Reserva Federal norteamericana) no estamos ante nuevas burbujas financieras; para otros, como Marc Faber (conocido analista de inversiones y empresario suizo), las burbujas están en todo lo que se refiere al sector financiero; otros que se sitúan en un término medio, como Nouriel Roubi- 
ni (profesor de la Universidad de Nueva York que se hizo célebre por prever la recesión que desencadenarían las hipotecas subprime), no las ven en los mercados de renta variable; pero sí las ven en los mercados inmobiliarios de algunos países. En todas estas declaraciones, las burbujas eran consideradas como algo indeseable para las economías nacionales.

Sin embargo, lo que realmente han hecho saltar a la arena pública el fenómeno de las burbujas con un acento distinto han sido las palabras pronunciadas por Larry Summers (ex-secretario del Tesoro americano y economista jefe del Banco Mundial entre 1991 y 1993) en una conferencia en el Fondo Monetario Internacional el pasado 8 de noviembre. Summers, después de decir que la depresión económica podría ser un estado más duradero de lo que se puede prever debido a una demanda todavía insuficiente, afirmó que la economía se aproxima al pleno empleo cuando hay burbujas que la impulsan. No es que Summers las defienda; pero las presenta como la única solución en una situación de permanente depresión. Las reacciones en contra de esta afirmación no se han hecho esperar en la prensa económica.

Este trabajo tiene un objetivo: con la ayuda de diversos trabajos académicos que han ido apareciendo en los últimos años, este artículo ofrece una descripción de las burbujas que sirva al misma tiempo como una invitación a tomar conciencia de sus efectos perversos para las sociedades en las que vivimos y para las economías que las sustentan. En el presente artículo se presentan las burbujas en el marco de un sistema financiero que tiene como objetivo servir al crecimiento y desarrollo sostenibles de la economía real. Las burbujas son presentadas aquí como un claro abandono de este servicio. Se presentan al final del artículo algunas sugerencias para impedir en lo posible la aparición de nuevas burbujas.

\section{EL SECTOR FINANCIERO AL SERVICIO DE LA ECONOMÍA REAL.}

El sistema financiero de un país es de vital importancia para el desarrollo de su economía real ya que facilita la trasferencia de capital desde las personas con recursos excedentarios hacia aquellas personas necesitadas de financiación para abordar sus actividades de inversión y consumo. Cuanto más robusto y equilibrado sea el sistema financiero más contribuye al desarrollo y crecimiento sostenibles tanto de la economía como de la sociedad de un país.

Un sistema financiero está compuesto por los bancos y las entidades de crédito en general, por las instituciones que organizan los distintos mercados financieros, por los reguladores bursátiles y del sistema bancario y por las entidades de servicios financieros. También forman parte de este sistema, las compañías aseguradoras y sus reguladores.

Un sistema financiero eficiente promueve el desarrollo económico de un país al permitir la canalización de recursos monetarios hacia actividades productivas 
como la industria, la construcción, la tecnología, la investigación e innovación y la expansión de los mercados. De esta forma el sistema financiero contribuye al desarrollo de una sociedad, ofreciendo soluciones para cubrir sus necesidades cotidianas.

De lo anterior se deduce que el centro de atención del sistema financiero no es el sistema financiero en sí mismo, sino la economía real del país. El sistema financiero tiene vocación de servicio subsidiario. El olvido de esta vocación acaba teniendo repercusiones negativas en la economía y en la sociedad de un país, como se ha podido comprobar en España en los últimos años.

Se parte de la crisis bursátil de 1987 porque, a pesar de ser una crisis breve, presenta una serie de síntomas que se van a repetir en el futuro. Estos síntomas ilustran un claro olvido de la función del sistema financiero y sus efectos negativos sobre la sociedad en general. El 19 de octubre de 1987 tenía lugar el llamado "Lunes Negro" bursátil: millones de inversores de Wall Street, presos del pánico, se lanzaron en masa a vender sus acciones. El crash se inició en Hong Kong, extendiéndose a Europa hasta alcanzar los Estados Unidos. El índice Dow Jones de valores industriales cayó 508 puntos, un 22,6\% y se vendieron 605 millones de acciones. Fue la mayor caída en un solo día (el 28 de octubre de 1929 el descenso fue del 12,8\%). Y en los demás mercados de valores tuvo lugar un descenso parecido. El pánico recorrió las principales bolsas de valores del mundo. Mucho se ha escrito sobre sus causas.

No había transcurrido todavía un mes desde aquello cuando el presidente del consejo de administración del entonces Banco de Bilbao, Sánchez Asiaín, tuvo una intervención haciendo colación a un discurso previo que tituló "Crisis de adecuación entre los sectores real y financiero» en la Real Academia de Ciencias Políticas y Morales. En torno a este discurso, el académico dijo (Sánchez Asiaín 1987, 83-84):

"Me refiero a esa posible crisis que se derivaría del hecho de que, entre todos, podríamos estar creando, casi sin quererlo, una superestructura financiera distorsionada y no fundamentada en bases reales. Decía entonces que no se trataba sino de una crisis potencial, de una crisis teórica, e invitaba a todos a pensar en los problemas que podría ocasionar un desarrollo no controlado, y cada vez más autónomo, del sistema financiero, tal como hemos empezado a ver que se está produciendo en los últimos tiempos. Especialmente, si fuera perdiendo contacto con las necesidades del mundo real, tal como empieza también a verse ahora. Llamaba la atención sobre lo preocupante que debería ser para todos nosotros el hecho de que en los últimos años, por ejemplo, los movimientos de capital a escala internacional hayan pasado a convertirse en el verdadero eje motriz de la economía mundial, registrándose, paralelamente, una notable y creciente desvinculación entre dichos movimientos y el flujo de bienes y servicios que debería darle soporte". 
A continuación, el académico ilustró este problema con algunos datos de entonces: el tráfico mundial de bienes y servicios para 1986, apenas representaba el $4 \%$ del movimiento de divisas que tuvo lugar en el mercado de Londres. El 90\% de las transacciones diarias en los mercados cambiarios nada tenían que ver con el comercio mundial, ni con inversiones directas productivas. Sólo un 5\% de los contratos negociados en los mercados de derivados se traducían en intercambio de mercancías. Tras estos ejemplos, continuaba diciendo (Sánchez Asiaín 1987, 84-85):

"Esta dinámica, y el excesivo protagonismo de lo financiero que de ella se deriva, podría estar llevando a los distintos intermediarios financieros a olvidar su verdadero papel en el sistema, que no es otro, que el de simples asignadores eficientes de unos recursos escasos. Con ello, la orientación de los flujos de capital estaría dependiendo, al final, no tanto de las necesidades reales de inversión existentes, sino de las oportunidades ofrecidas a corto plazo para obtener mayores rendimientos en la colocación del ahorro. Si esto fuera así, decía entonces, estaríamos corriendo el riesgo de utilizar el formidable potencial de crecimiento y adaptación del mercado global, para soportar financieramente situaciones artificiales, cuando no indeseables, de la economía real, retrasando los necesarios ajustes. Y ello, tanto en el plano micro, como en el macroeconómico. Porque el resultado de esta eventualidad no sería otro, a nivel macroeconómico, que el recorte de las posibilidades de crecimiento futuro de la economía mundial. Y a nivel microeconómico, el enmascaramiento financiero de situaciones económicamente no viables.

En todo caso, concluía, si esto sucediera, estaríamos poniendo los cimientos de un universo financiero en permanente expansión, y caracterizado por su carencia de equilibrio. Y por ello, deforme, ineficaz, sobredimensionado, y sin legitimación, por encontrarse desconectado de las demandas sociales.

Optimista siempre, como soy, decía que esta sobredimensión no sería permanente, porque el mercado destruiría a la larga la parte inadaptada, aunque tal proceso de rectificación sería muy costoso, y entrañaría, en todo caso, un despilfarro considerable de recursos. A la vista de las consecuencias de la crisis bursátil que estamos viviendo, temo que esa previsión se está haciendo operativa, porque el mercado, y en unos pocos días, está eliminando, o reduciendo a sus justos límites, y de manera brutal, un conjunto de instituciones financieras, que se han visto mayormente afectadas por la caída de las cotizaciones. Sirva como ejemplo extremo la Bolsa de Hong Kong, que ha tenido que cerrar una semana su mercado por quiebra de la mayor parte de sus agentes intermediarios. Veremos más cosas. Y ello, porque los mercados financieros son implacables, y porque operan con gran rapidez. Y, desde luego, porque cada vez toleran menos la ineficiencia". 
A juzgar por la fecha en que se pronunció y con la perspectiva que da el tiempo cuando aún estamos sufriendo las consecuencias de la crisis financiera y económica que comenzó en 2007, este discurso tiene indudables tintes proféticos. Aunque se quedó corto en sus previsiones cuando dijo: "Caminamos hacia un sistema financiero en el que trasladar cargas a la sociedad va a resultar cada día más excepcional".

Ha sido necesario reflejar esta larga cita porque en ella se contiene lo que siempre aparece en el ojo de los huracanes financieros: el distanciamiento entre el sistema financiero y la economía real. Resulta interesante que este fragmento del discurso contiene en sí mismo muchas ideas que parecen olvidadas cuando comenzó la crisis financiera del 2007:

1.- El sistema financiero debe estar al servicio de la economía real. Para ello los intermediarios financieros deben ser asignadores eficientes de unos recursos que son escasos: el dinero excedentario de unos deben ser invertidos eficientemente en proyectos de inversión productivos que desarrollen la economía de un país o región. Si esto se consigue, el sistema financiero estaría sustentado sobre una base realista, estaría ayudando a la producción de bienes y servicios, los movimientos de capitales estarían vinculados a los flujos de mercancías y se estaría atendiendo a las necesidades del mundo real.

2.- El primer síntoma que surge cuando el sistema financiero se distancia de la economía real es su propio sobredimensionamiento, que se concreta en una mayor presencia de las instituciones financieras (bancos) en detrimento del resto de las instituciones económicas (empresas), un mayor protagonismo de los mercados financieros en detrimento de los mercados de bienes y servicios y, finalmente, un mayor peso de los instrumentos financieros en detrimento de los bienes y servicios en los intercambios económicos producidos en un país.

3.- Los mercados acaban corrigiendo ese distanciamiento de una forma muy abrupta e indeseable por muchos. En esa corrección muchos intermediarios financieros desaparecen de la arena económica y muchos inversores pierden el valor de sus inversiones y ahorros. Las cargas de esta corrección se acaban trasladando a la sociedad, con el incremento del desempleo tras la bancarrota de muchas empresas. Es lo que muchos llaman el efecto sistémico de un desequilibrio.

4.- Este alejamiento del sistema financiero de la economía real y sus consecuencias le acaban restando eficacia, credibilidad y legitimidad social para aspirar a ser un sistema autorregulado. Desde la sociedad se acaba mirando al sistema financiero con sospecha y necesitado de un mayor control estatal.

Todas estas ideas podrían considerarse como aprendizajes de una crisis financiera como fue la crisis bursátil de 1987. Todas las explicaciones a esta crisis incluyen un elemento común: la sobrevaloración de los activos financieros. Sin 
embargo todos estos aprendizajes no debieron estar muy presentes en la mente de quienes trabajan en las instituciones que constituyen el sistema financiero, cuando después de aquella crisis tuvieron lugar otras dos: el estallido de la burbuja bursátil de las empresas punto.com y la actual crisis financiera y económica internacional que se inició en agosto de 2007. De ambas crisis hablaremos más adelante.

A la vista de estas crisis financieras es fácil recordar las palabras de Galbraith (1994, 53): "la memoria financiera es breve". En todas estas crisis ha habido un sobredimensionamiento del sector financiero que se ha manifestado en una sobrevaloración de los activos en los respectivos mercados: una sobrevaloración de las cotizaciones de las acciones en los mercados bursátiles y una sobrevaloración del valor de la vivienda en los mercados inmobiliarios. Parece como si los aprendizajes de las crisis pasadas no fueran suficientes.

\section{LA DESVINCULACIÓN DEL SISTEMA FINANCIERO CON LA ECONOMÍA REAL: BURBUJAS FINANCIERAS E INMOBILIARIAS.}

Las burbujas financieras e inmobiliarias representan la señal más clara de que el sistema financiero se ha desligado de la economía real. Pero, ¿qué es exactamente una burbuja en el contexto financiero? Minsky, Shiller y Kindleberger han explicado ampliamente el fenómeno de las burbujas en el campo financiero con sus fases.

Una burbuja es un fenómeno que se produce en los mercados financieros e inmobiliarios que se caracteriza por una subida exagerada y prolongada del precio de un activo o producto, de forma que dicho precio se aleja cada vez más de su valor fundamental o intrínseco, hasta el momento en que se produce un desplome de ese precio.

Para poder entender qué es una burbuja hay que recordar que los activos -valores mobiliarios, divisas, oro, materias primas, etc.- que se intercambian en los mercados financieros e inmobiliarios son valorados a partir de los futuros flujos de caja que puedan generar. Ya sea utilizando un sistema de múltiplos comparables o de descuentos de los flujos de caja que se espera que generen, en el centro de la valoración de un activo financiero se encuentra las expectativas que se tengan en torno a dicho activo. Estas expectativas son creadas a partir de la información financiera disponible acerca del emisor del activo (generalmente una compañía) y acerca del mercado o sector en el que se desenvuelve el emisor. Al valor de un activo obtenido en función de sus futuros flujos de caja esperados se le conoce como valor intrínseco o valor fundamental. Cuando un activo está sobrevalorado o infravalorado se dice que existe una anomalía temporal en el mercado que hace que su precio esté alejado de los fundamentales de la empresa que emite dicho ac- 
tivo y por tanto se espera una corrección de dicho precio en el mercado: subiendo si está infravalorado, bajando si está sobrevalorado.

Una burbuja es un proceso que culmina en una sobrevaloración de los activos de un mercado como consecuencia de una desvinculación del precio con el valor que se deduce de un análisis de la información financiera disponible (conocido también como "análisis fundamental") de dichos activos. Si existe tal desvinculación, si el precio en el mercado tiene poco que ver con la situación presente y con las expectativas futuras de dichos activos, entonces ¿con qué se vincula el precio? Generalmente con movimientos especulativos en torno al valor de dicho activo.

Para que la burbuja tenga lugar, esta desvinculación del precio con los valores intrínsecos de los activos ha de ser persistente en el tiempo. Se da una subida permanente del precio, retroalimentada con la confianza de los inversores de que a corto plazo dicho precio no va a caer.

Pero vuelve a surgir la pregunta: ¿qué causa esta persistencia de la subida de los precios de los activos que no obedecen a las valoraciones fundamentales? Se han tratado de dar muchas explicaciones.

En un trabajo publicado recientemente, Cauwels y Sornette (2012) defienden que la actual crisis financiera y económica internacional es el resultado de una serie de burbujas financieras que se han ido solapando unas con otras en los últimos años:

\section{a) La burbuja de las empresas pertenecientes a la llamada "nueva economía" (empresas punto.com y empresas biotecnológicas) que tuvo lugar en el periodo $1995-2002$}

Como se puede observar en el gráfico 1, el índice Nasdaq es fiel reflejo de lo que supuso la burbuja de las empresas tecnológicas. 
Gráfico 1. Índice Nasdaq

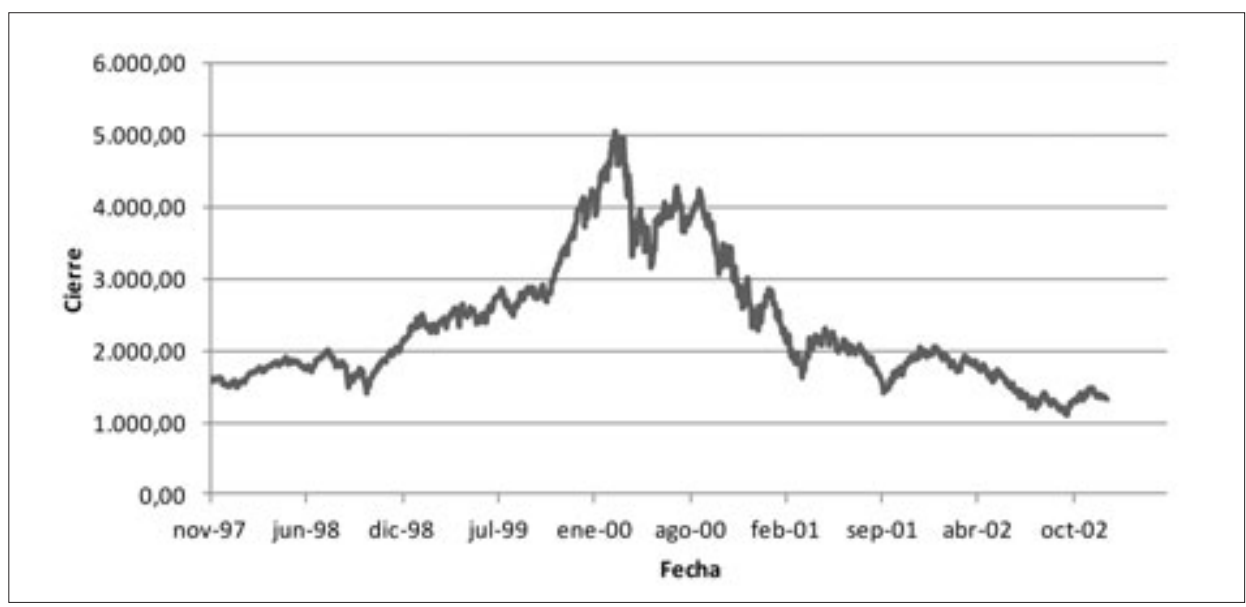

Fuente: Elaboración Propia a partir de los datos suministrados por Infobolsa.

El viernes 10 de marzo de 2000, el índice tecnológico Nasdaq marcó su máximo histórico, más del doble de su valor que un año antes. El lunes 13 de marzo tuvo lugar una reacción en cadena de ventas de títulos, reforzada por el pánico de los inversores minoristas e institucionales. En tan sólo seis días, el Nasdaq perdió casi el nueve por ciento de su valor. De marzo de 2000 a octubre de 2002, las empresas tecnológicas tuvieron una pérdida de valor de 5.000 millones de dólares. Es importante señalar que para luchar contra los efectos negativos de un mercado bursátil colapsado por el estallido de esta burbuja, la Reserva Federal norteamericana se embarcó en una política monetaria proactiva, bajando los tipos de interés del 6,5\% en el año 2000 al 1\% en los años 2003 y 2004. Esta bajada de tipos de interés permitió que se pudiera pedir prestado dinero más barato con la esperanza de que estos préstamos sirvieran para que las compañías invirtieran en proyectos futuros, generando con este apalancamiento un mayor valor presente de los activos financieros. Esta política monetaria proactiva fue apoyada por iniciativas legislativas del Congreso de los Estados Unidos consistentes en una mayor desregulación del sistema y que se concretaron en la supresión de límites regionales y sectoriales de los grandes bancos en los mercados financieros, así como la legalización de holdings bancarios (shadow banking system) para la realización de cualquier negociación bancaria.

\section{b) La burbuja inmobiliaria (2003-2006)}

Esta política monetaria proactiva de la Reserva Federal junto con las iniciativas del Congreso para expandir el mercado inmobiliario alimentaron la burbuja 
inmobiliaria norteamericana. Como consecuencia de los bajos tipos de interés el margen de intermediación bancaria decrece. Para aumentar el margen los bancos deciden conceder préstamos más arriesgados por los que podrían cobrar más intereses. Las garantías de los préstamos hipotecarios se relajan bajo el espejismo de que un bien cuyo precio no baja es la mejor garantía para conceder esos préstamos. Esto permite el acceso a un número creciente de personas que recibiendo estos préstamos proceden a comprar sus viviendas. En el gráfico 2 se puede observar la evolución del índice de precios reales de la vivienda en Estados Unidos.

\section{Gráfico 2. La Burbuja Inmobiliaria en EEUU}

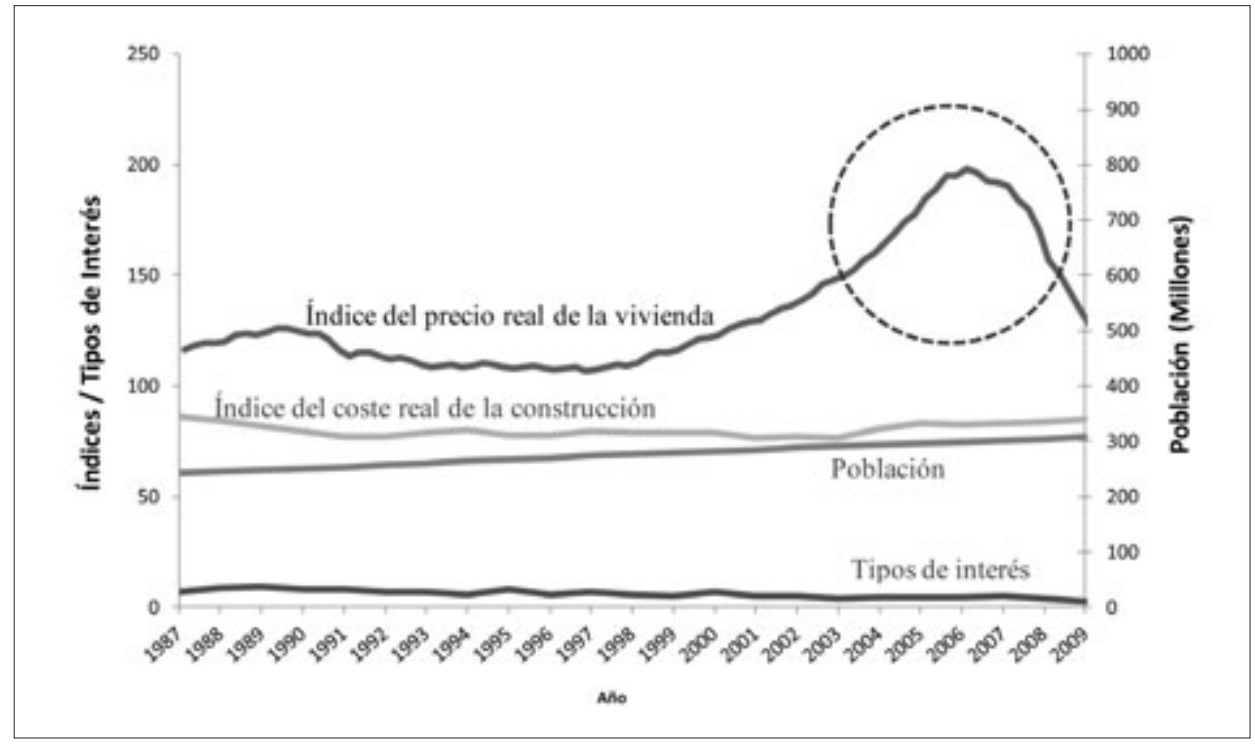

Fuente: Elaboración propia a partir de datos recogidos por Robert J. Shiller, para Irrational Exuberance, 2nd. Ed., Princeton University Press, 2009.

A la vista de este gráfico, llama poderosamente la atención el incremento del margen existente entre el índice del precio de la vivienda y el índice del coste de su construcción.

\section{c) La burbuja de los créditos titulizados (2004-2007)}

Una segunda medida de los bancos para ensanchar el margen de intermediación bancaria fue la de aumentar el número de operaciones; pero este objetivo chocaba con dos barreras: el dinero en poder de los bancos para con- 
ceder esos préstamos no era ilimitado y además Basilea II, en aras a garantizar la solvencia de los bancos, les exigía tener un capital mínimo en función de sus activos.

Para no interrumpir la cadena de concesión de préstamos hipotecarios, poder acceder a más dinero y cumplir con los requisitos de Basilea II, los bancos procedieron a la titulización de los préstamos empaquetándolos en títulos conocidos como MBS (Mortgage-Backed Securities o bonos garantizados por hipotecas), activos que son creados y vendidos para sacarlos de balance y poder obtener nuevos fondos con los cuales financiar la concesión de nuevos préstamos hipotecarios.

Para sacarlos de balance los propios bancos crearon los SIV (Structured Investment Vehicles o Vehículos de Inversiones Estructuradas) que son unas instituciones virtuales que escapaban a la consolidación de sus balances con los balances de los bancos que los crearon. Los SIV compraban una buena parte de los MBS quienes a su vez los vendían a otras instituciones financieras. Para la venta del resto de los MBS, se contrataban los servicios de la banca de inversión quienes colocaban esos MBS a Fondos de Inversión, Sociedades de Capital Riesgo, Compañías de Seguros, etc.

Los bancos de inversión, combinaron estos MBS (aparentemente con riesgo bajo) con otros bonos respaldados por activos diversos y con un riesgo mayor creando así otros títulos llamados CDO (Collateralized-Debt Obligations u obligaciones de deuda garantizadas). Dentro de un CDO, esta combinación de bonos se hace a través de tramos (tranches) con distintos riesgos: desde riesgos muy altos (equity) a riesgo muy bajo (senior), con la idea de que el tramo con menos riesgo sirviera de cobertura mínima frente al tramo más arriesgado. Con el CDO se pretendía conseguir mayores rentabilidades con un riesgo aparentemente más diversificado. El problema que no se vio (o no se quiso ver) es que tanto los MBS como los $\mathrm{CDO}$ son activos cuyos valores en el mercado son muy sensibles a la variación de los tipos de interés y al comportamiento de los precios de los inmuebles. Fue precisamente la caída del precio de los inmuebles lo que produjo una caída del valor de estos títulos.

En el siguiente gráfico se puede observar la evolución del tamaño del mercado mundial de derivados de crédito: 


\section{GRÁFICO 3. Mercado mundial de Derivados de Crédito}

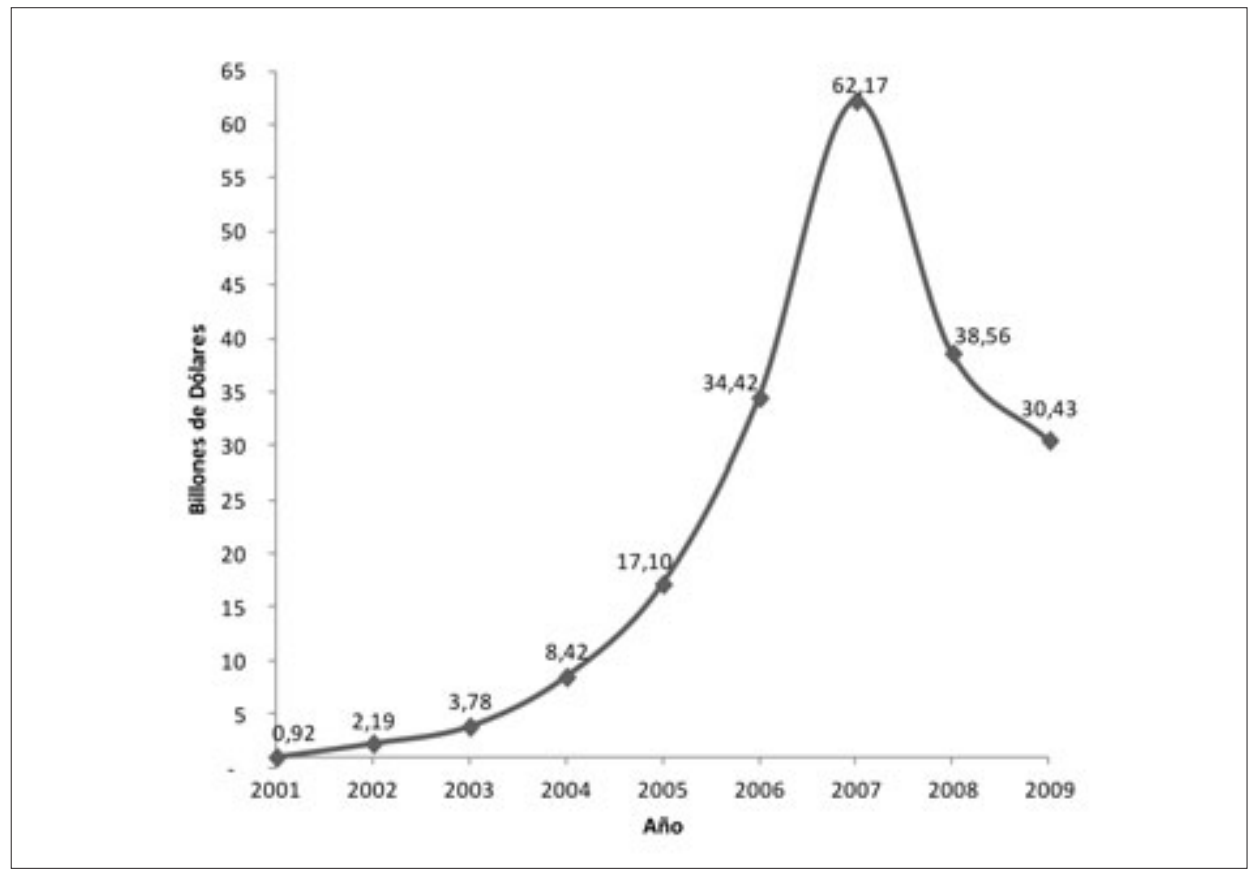

Fuente: Elaboración propia a partir de los datos facilitados por International Swaps and Derivatives Association.

En junio de 2007, el tamaño era de 45,47 billones de dólares, alcanzando los 62,17 billones de dólares seis meses más tarde. Para hacerse una idea de la magnitud de estas cifras basta recordar que el PIB de los Estados Unidos al final de 2007 era de 13,78 billones de dólares, y el de España, 1,36 billones de dólares.

Además de las razones que han llevado a la creación de estos productos financieros, la complejidad de los algoritmos estadísticos utilizados para estructurar estos derivados y la falta de recorrido histórico con estos productos han conducido a la creación de unas expectativas exorbitadas de grandes retornos asociados a una percepción irrealista de un riesgo bajo.

\section{d) La burbuja bursátil (2004-2007)}

Las burbujas anteriores acabaron teniendo incidencia en los mercados bursátiles, como se puede apreciar en el gráfico 4, que recoge la variación acumulada (en escala logarítmica) de varios índices bursátiles del mundo. 
Gráfico 4. Evolución de los principales índices bursátiles (variación acumulada)

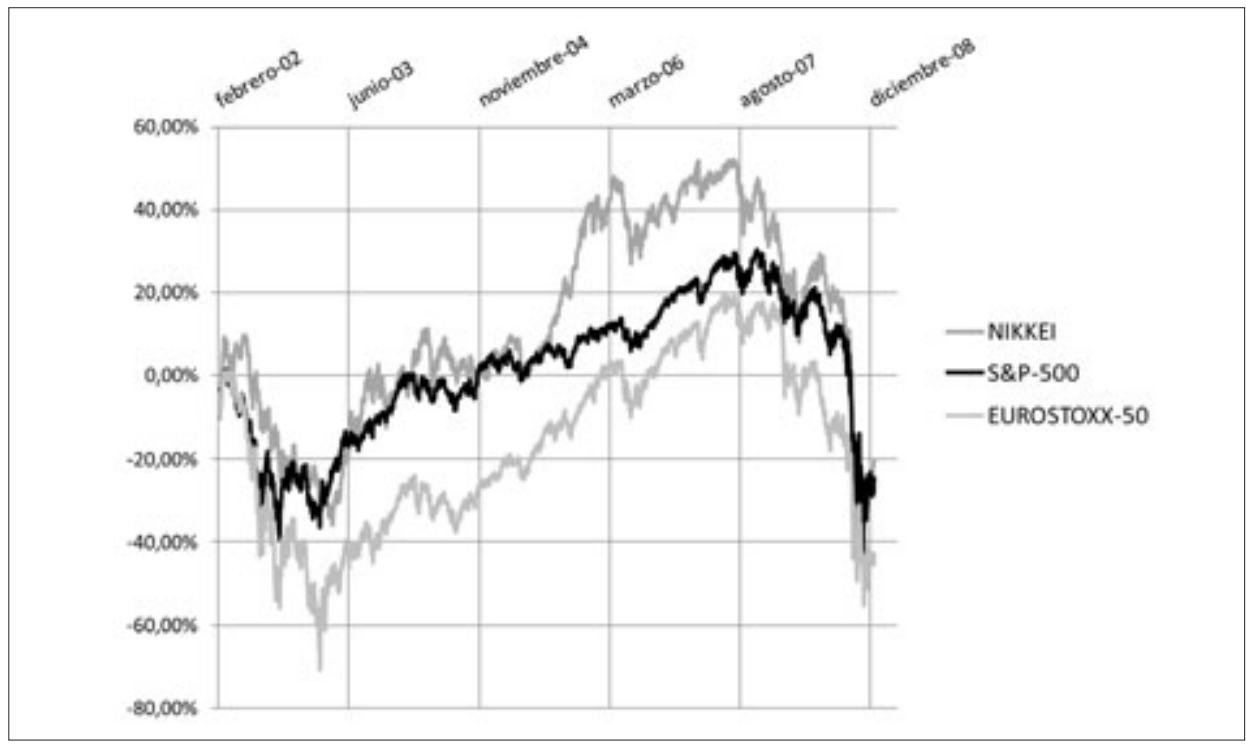

Fuente: Elaboración propia a partir de los datos suministrados por Infobolsa.

Se puede observar que mientras tenían lugar las anteriores burbujas, los índices bursátiles se resistían a moderar su tendencia invariablemente alcista.

\section{e) La burbuja de las materias primas (2006-2008)}

La burbuja de las materias primas es un ejemplo de interconexión de todas las burbujas mencionadas hasta ahora: El crecimiento de las burbujas inmobiliaria, de los derivados del crédito y de los mercados bursátiles llevaron a la creación de dinero disponible que fue utilizado para una mayor demanda de materias primas. Los gráficos 5 y 6 reflejan un exorbitado crecimiento de los precios que hablan más de movimientos especulativos que de demanda real. 
Gráfico 5. Precio Cereales

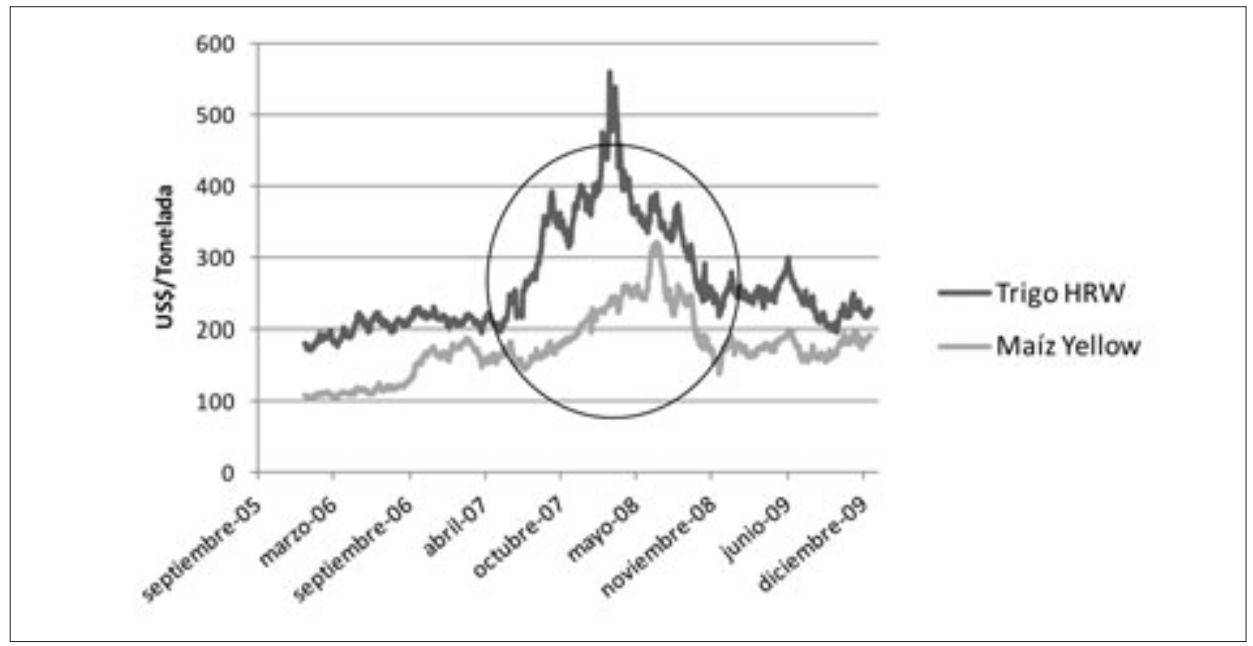

Fuente: Elaboración propia a partir de datos de Odepa y Reuters.

\section{Gráfico 6. Precio Oro y Petróleo}

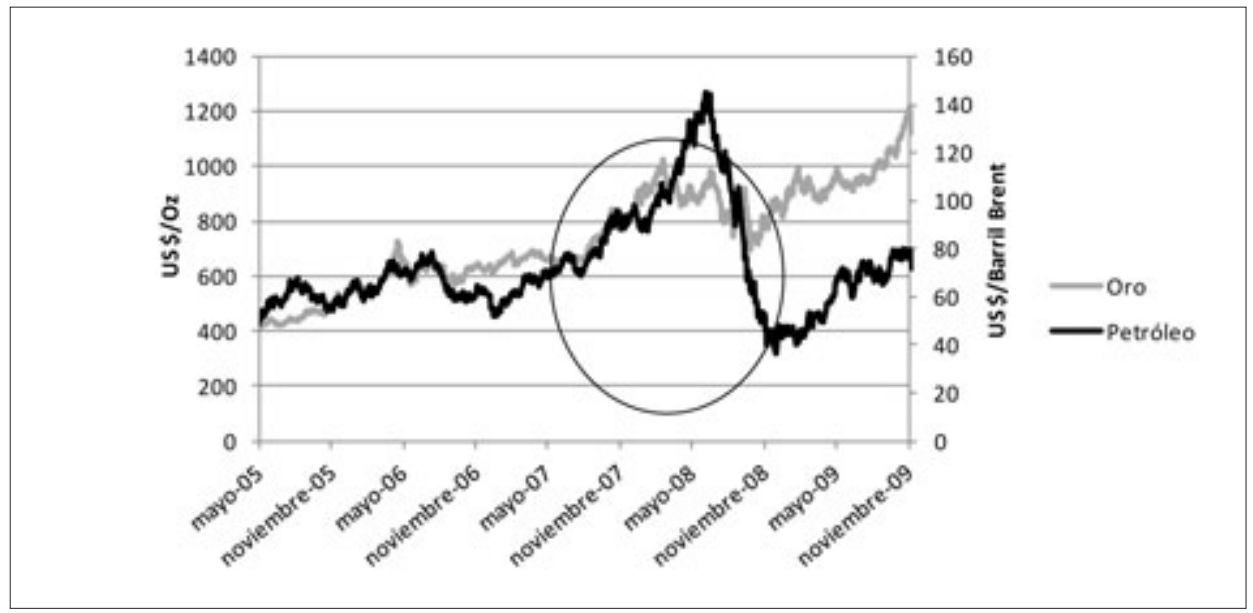

Fuente: Elaboración propia a partir de datos de Infobolsa

En cuanto al petróleo, en noviembre de 2006 el precio del barril Brent era de 57,87 dólares; ese precio alcanza la cifra de 145,04 dólares en julio de 2008 para volver a bajar hasta 39,74 dólares en diciembre de ese mismo año. El oro también experimentó una oscilación que habla de burbuja: en enero de 2006 la onza de 
oro cotizaba a 520,75 dólares; esa cotización alcanza el precio de 1.023,5 dólares en marzo de 2008 para volver a bajar a 692,5 dólares siete meses más tarde.

También el precio internacional de los principales cereales tuvo fuerte oscilaciones que nos hablan de burbujas especulativas. El trigo HRW tenía un precio (FOB USA) de 170,03 dólares por tonelada en enero de 2006; alcanzó la cifra de 537,66 dólares en marzo de 2008 para volver a bajar nueves meses más tarde y cotizar a 216,15 dólares por tonelada. El maíz clase yellow tenía un precio (FOB USA) de 102,08 dólares por tonelada; alcanzó los 319,98 dólares en junio de 2008 para volver a bajar seis meses más tarde a 137,31 dólares.

\subsection{La ilusión de la máquina de dinero perpetuo.}

Cauwels y Sornette (2012) ofrecen así evidencia suficiente de un conjunto de burbujas que hemos reproducido aquí a partir de datos disponibles en los mercados.

Estas burbujas están interrelacionadas y se han ido alimentando mutuamente. Según estos autores, la causa de este proceso se encuentra en lo que ellos llaman "la ilusión de la máquina de dinero perpetuo": con este término se quiere dar a entender la creencia de que es posible crear riqueza desde la mera apelación al crédito y a las innovaciones financieras que multiplican la expansión del crédito, pero sin que este crédito tenga relación con la economía productiva. De la misma manera que la máquina de movimiento perpetuo es un sueño imposible que viola las más elementales leyes de la física, es imposible para una economía que crece anualmente a una tasa real del 2\%-3\% ofrecer beneficios anuales del 10\%-15\%.

La ilusión de la "máquina de dinero perpetuo" ha posibilitado la creación de estas burbujas, permitiendo a los participantes del sistema financiero extraer dinero en un proceso artificial e insostenible a medio y largo plazo. Desde la visión de un sistema financiero al servicio de la economía real, lo que Cauwels y Sornette (2012) denuncian en su trabajo es que el sistema financiero ha generado dinero en un proceso que poco tiene que ver con la creación de bienes y servicios propios de una economía real productiva.

Un efecto de esta ilusión puede ilustrarse en el gráfico 7 a través de la comparación entre la evolución del consumo privado (como porcentaje del PIB) y la de los salarios (como porcentaje del PIB) para las áreas más desarrolladas del mundo: 


\section{Gráfico 7. Consumo Privado-Salarios (EEUU+UE+Japón)}

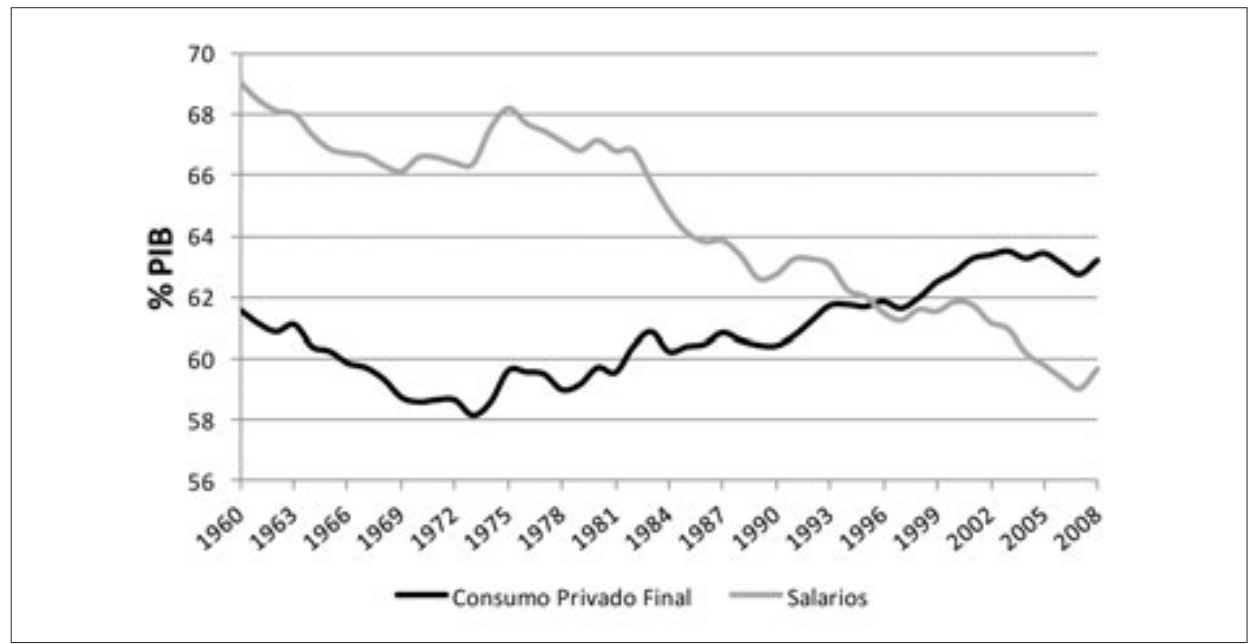

Fuente: Elaboración propia a partir de los datos de AMECO

Desde los años setenta, el consumo privado se apoya menos en los salarios. A partir de 1996, el consumo deja de estar apoyado en su totalidad por los salarios para depender también de los beneficios financieros (Cauwels y Sornette, 2012). $\mathrm{Si}$ estos beneficios financieros provienen de activos sobrevalorados, ya se puede ver el efecto negativo que sobre las economías domésticas tiene una fuerte corrección de los mercados, como la que se produce con el estallido de una burbuja financiera.

\subsection{El efecto negativo de las burbujas.}

Todas estas burbujas ponen en evidencia el alejamiento del sistema financiero de su auténtica función que es estar al servicio de la economía real. Llama la atención que esta separación entre sistema financiero y economía real se ha dado también en el mundo de la investigación académica, como denuncia Werner (2012). Según este profesor, en el mundo académico la investigación sobre la economía, con su potencial para captar aspectos sistémicos y macroeconómicos, se ha realizado al margen de la disciplina financiera y bancaria, con su potencial para reflejar el comportamiento del sistema financiero y sus efectos sistémicos en un modelo.

Werner (2012) explica muy bien el efecto negativo de una burbuja alimentada por el recurso al crédito bancario: la concesión de un crédito grande y mantenido en el tiempo que no va dirigido a la creación de riqueza (medida ésta como incre- 
mento del PIB) producirá un esquema Ponzi, donde los que entraron al comienzo de la burbuja tienen la oportunidad de salir con beneficios, mientras que los que entraron de forma tardía (normalmente el público en general que, atraídos por la subida de los precios anunciada en los medios de comunicación, compraron el activo a un precio próximo al máximo de la burbuja) van a perder. Werner llega a afirmar que toda ganancia producida por una elevación de los precios de los activos sin que obedezca a una creación de riqueza es un juego de suma cero, donde las ganancias de unos provienen de las pérdidas de otros.

\subsection{En busca de culpables.}

Cuando una burbuja estalla con sus dolorosas consecuencias, comienza la búsqueda de los culpables que con su trabajo contribuyeron a crearlas. En el pasado se ha culpado a los contables por manipular los estados financieros de la empresa con el fin de elevar su precio o cotización. Se ha culpado a los administradores de la empresa por haber tomado decisiones cortoplacistas en búsqueda de un incremento artificial del precio de las acciones de la compañía para así beneficiarse de los stock options con los que fueron remunerados.

Se ha culpado a los auditores de dar su conformidad a estados contables alejados del verdadero valor patrimonial de compañías, con el fin de no perderlas como clientes. Se ha culpado a las agencias de rating por haber otorgado interesadamente una calificación segura a la deuda emitida por empresas en dificultades o con colaterales de dudosa liquidez o valoración.

Se ha culpado a los analistas financieros de haberse dejado llevar por sus conflictos de interés y exagerar sus expectativas optimistas acerca del valor de un activo. Se ha culpado a los gestores profesionales de carteras de inversión por realizar una asignación de activos más arriesgada, ignorando interesadamente las señales de sobrevaloración de activos. Se ha culpado a los bancos de alimentar interesadamente con sus créditos estas inversiones en activos sobrevalorados haciendo caso omiso al riesgo que estaba asumiendo y al perfil de su cliente. Se ha acusado a los reguladores de mirar para otro lado e incluso de dejar que el sistema se autorregulara pensando ingenuamente que así sería más eficiente. Se ha culpado a los inversores que han perdido gran parte (si no todo) del valor de sus inversiones por ser demasiado codiciosos.

Se ha culpado también a los académicos de las universidades más prestigiosas del mundo por incentivar la creencia de que los mercados son eficientes y no atender a factores humanos que rompen la racionalidad clásica del mundo financiero.

Como se puede observar, el catálogo de culpables es largo. Lo cual pone en evidencia que todo un sistema se olvida de su auténtica función y se acaba mirando sólo a sí mismo y los intereses particulares de quienes actúan en él. España no ha sido ajena este fenómeno. 


\section{EL CASO ESPAÑOL: LA BURBUJA INMOBILIARIA.}

De todos es conocido que la principal protagonista de la crisis económica y financiera en España ha sido la burbuja inmobiliaria cuyo estallido ha producido una acusada caída del precio de la vivienda -llevándose gran parte del valor de los ahorros y de los bienes de muchos españoles- un descenso de unidades vendidas y un considerable número de empresas promotoras y constructoras declaradas en quiebra (aumentando así el desempleo) o con serias dificultades financieras, además de una drástica reducción de las industrias auxiliares. Como se verá a continuación, la burbuja inmobiliaria es el efecto conjunto de dos burbujas: una burbuja del crédito hipotecario y una burbuja en los precios de los inmuebles.

Desde aproximadamente 1985 la industria de la construcción española experimentó un notable crecimiento, en un contexto internacional donde esta industria también se estaba expandiendo. El caso español se caracterizó por un incremento acentuado de viviendas construidas y un crecimiento sin precedentes de los créditos hipotecarios, así como un aumento del peso de la construcción en el PIB y un crecimiento del empleo en el sector.

\section{Gráfico 8. Precio de la vivienda - IPC}

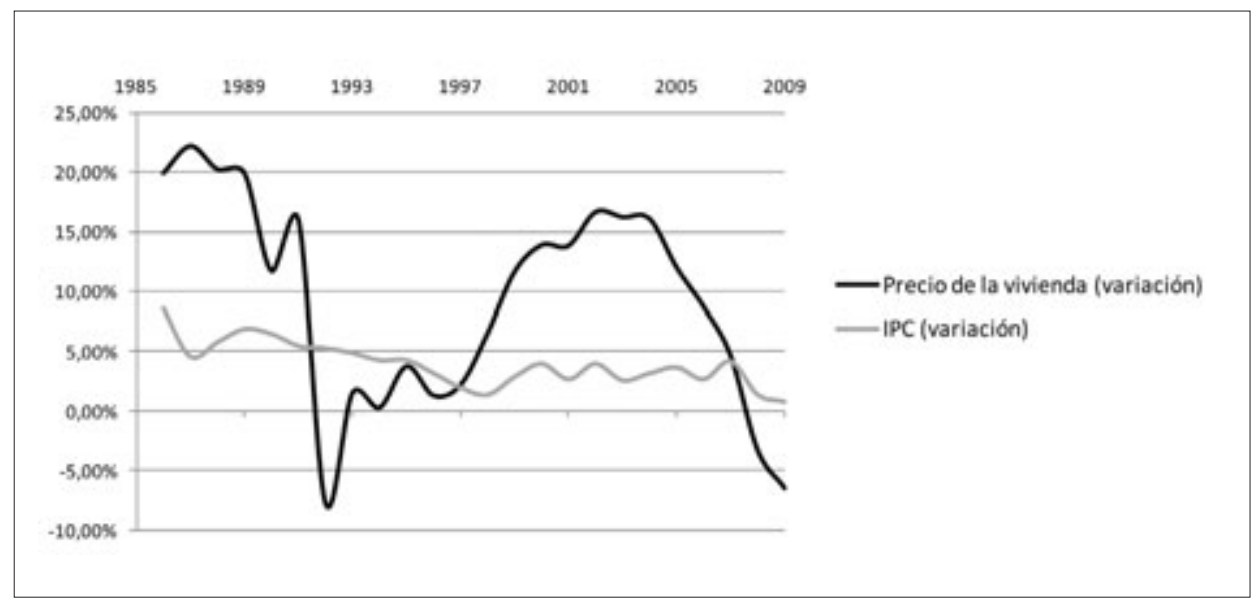

Fuente: elaboración propia a partir de datos del INE

Junto a esta expansión hubo a partir de 1992 un incremento de los precios de la vivienda muy por encima del IPC, como se puede observar en el gráfico 8:

Como en las burbujas descritas en los anteriores apartados, el incremento de precios fue un fenómeno parejo a la expansión del crédito hipotecario en un entorno donde los tipos de interés eran bajos, como muestran muy bien Gimeno y 
Martínez-Carrascal (2010). Como se puede observar en el gráfico 9, los precios de la vivienda subieron entre el $16 \%$ y el $17 \%$ anual entre 2003 y 2005 , mientras el IPC lo hacía por debajo del 5\% y las rentas del trabajo lo hacían en torno al 6\% por término medio.

\section{Gráfico 9. Mercado Inmobiliario Español}

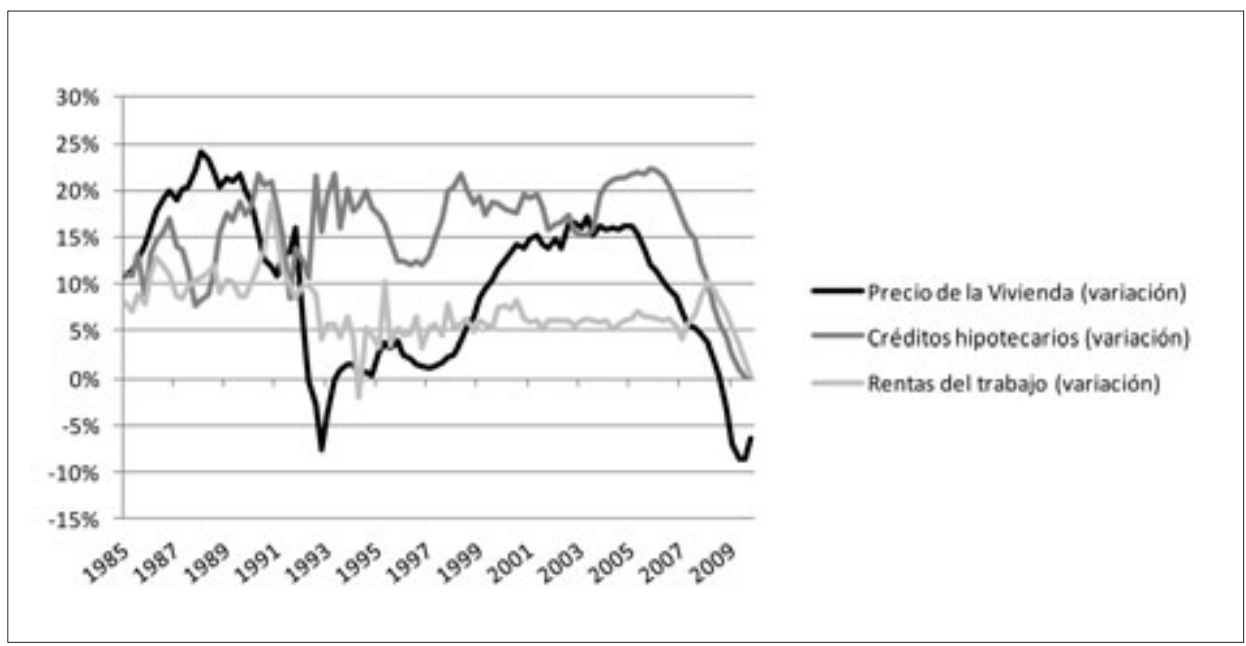

Fuente: Gimeno y Martínez-Carrascal (2010).

El anterior gráfico ilustra el grado de apalancamiento de las familias españolas que adquirieron viviendas en el periodo estudiado. Entre 1997 y 2005, el crecimiento del crédito hipotecario era por término medio de $18,5 \%$ anual, cuando las rentas del trabajo crecieron al 6,18\% de media anual.

Este incremento de las rentas de trabajo no justifica una mayor capacidad de endeudamiento como el que se materializó con los créditos hipotecarios otorgados. ¿Qué justifica entonces una mayor capacidad de endeudamiento por parte de los hogares españoles? El incremento del precio del activo que servía como colateral a los créditos, es decir, de las viviendas. También las sociedades inmobiliarias y las constructoras se endeudaron para aprovechar una demanda que confiaba en un alza de los precios que no parecía tener fin. Al final, el crédito estuvo al servicio de (y alimentó) una sobrevaloración y, por consiguiente, se situó fuera de su objetivo de productividad sostenible.

Lo que hace especialmente grave a esta burbuja es el hecho de que el crecimiento económico en España se ha basado en este sector claramente sobredimensionado. Se incurrió en la ilusión consistente en que el precio de un activo como el inmobiliario no bajaría nunca. 
En otoño de 2006 tiene lugar la inflexión en el avance del crédito hipotecario y los precios de las viviendas comienzan a caer. Además de los factores coyunturales internacionales, existen factores que han hecho de catalizadores de esta caída de los precios: la fuerte especulación, el exceso de oferta y la incapacidad de la demanda para asumir los elevados precios de los inmuebles.

En el año 2008 muchas inmobiliarias cerraron. Especialmente sonadas fueron las noticias de dos inmobiliarias españolas: en mayo, Don Piso, que había llegado a tener 400 oficinas, cierra todas sus oficinas y despide al 100\% de su plantilla tras registrar una caída de ventas del 66\%. En julio, la principal inmobiliaria española, Martinsa-Fadesa, protagoniza la mayor suspensión de pagos de la historia económica del país. La deuda del grupo se estimó en más de 7.000 millones de euros.

\subsection{El papel del regulador.}

El estallido de las burbujas financieras viene siempre acompañado por una búsqueda implacable de los culpables que la provocaron. Y el primer ataque se reserva a las autoridades monetarias que la permitieron. Especialmente duras fueron las críticas que lanzó el diario The New York Times, el 27 de junio de 2012 a tres miembros españoles del Fondo Monetario Internacional (FMI), que ocupando cargos relevantes en el Banco de España no supieron anticipar el problema que se cernía sobre la burbuja inmobiliaria: "Mientras España se acercaba a la crisis inmobiliaria y bancaria que ha provocado el rescate a los bancos, los líderes financieros en puestos influyentes mayoritariamente restaron importancia a las preocupaciones acerca de que algo marchaba terriblemente mal", afirma el diario.

La crítica más recurrente ha sido que el regulador no quiso afrontar el problema. Sin embargo, el regulador bancario afrontó directamente al problema, aunque lo hizo tímidamente, como se demostrará a continuación, analizando los informes anuales que hizo públicos en sus debidos momentos.

El Banco de España constató en el Informe Anual 2001, presentado en junio de 2002, que:

"Teniendo en cuenta que los bienes inmobiliarios suponen, aproximadamente, un 70\% de la riqueza total de los hogares españoles y son utilizados como garantía de préstamos que suponen en torno a un $40 \%$ del crédito total concedido por las entidades españolas, el análisis del precio de la vivienda cobra una especial relevancia para la valoración de la situación económica en nuestro país" (p. 109).

Subrayaba el informe que tanto el precio de los pisos como los créditos hipotecarios habían crecido de forma intensa en los últimos años, y que tanto las familias como los bancos que habían concedido los créditos estaban más expuestos 
no sólo a un aumento de los tipos de interés (los préstamos son en su mayoría a tipos variables) como a un posible descenso del valor de los activos inmobiliarios. Recordaba el Banco de España que los factores de carácter estructural (fiscalidad atractiva, preferencia por la vivienda en propiedad, aumento de la población en edad de formar hogar, aumento del turismo residencial), aun con ser importantes, podrían resultar insuficientes para justificar en su totalidad el fuerte aumento del precio de los pisos, lo que podría conllevar el riesgo de una posible corrección futura. Frente a esta advertencia del banco regulador, las asociaciones de promotores inmobiliarios no veían razones suficientemente objetivas para una corrección de precios. Es decir, en este informe ya se avisa de un aumento de los precios de los inmuebles que no hace justicia a sus fundamentales.

En el Informe Anual 2002, vuelve a recordar que los créditos hipotecarios han aumentado a tasas interanuales del 20\%, lo cual no está exento de riesgos, muy especialmente cuando "existe evidencia de una cierta sobrevaloración de los precios de la vivienda" (pp.129-130). Aparece ya, aunque tímidamente, el calificativo de sobrevaloración.

En el Informe Anual 2003, avisa del elevado endeudamiento de los hogares: alrededor del 70\% de estos créditos están relacionados con la vivienda (p.30) que se materializan en préstamos a interés variable, lo cual se expone al riesgo de tipos de interés. La vivienda en propiedad representaba entonces las tres cuartas partes del patrimonio familiar. Y vuelve a recoger la sobrevaloración:

\begin{abstract}
"Aunque, como ocurre con cualquier activo, es muy difícil calibrar con precisión su nivel de equilibrio, la estimaciones disponibles sugieren la existencia en los últimos años de una cierta sobrevaloración que durante 2003 se mantuvo, ya que según los últimos datos publicados por el Ministerio de Fomento los precios crecieron un $17 \%$ en dicho año" (p.32).
\end{abstract}

Antes de la publicación de este informe, en su Boletín Económico de septiembre de 2003, se informaba de una sobrevaloración de casi el 20\% sin mencionar la palabra burbuja. Pero decía algo más: la vivienda se está utilizando como un activo de inversión, además de bien necesario para los nuevos hogares. Es decir, la demanda de la vivienda no sólo está siendo impulsada por la población en edad de formar hogar, sino por inversores que ven en el bien inmobiliario un activo cuya revalorización ofrece beneficios muy altos. Los medios de comunicación publicaron esta advertencia del Banco de España y lo hicieron con el término "burbuja inmobiliaria".

El Informe Anual 2004 del Banco de España empieza a hacerse eco de lo preocupante que resulta el elevado endeudamiento de las familias (que no ha dejado de crecer) y de la sobrevaloración de los activos inmobiliarios. En este año, las deudas de los hogares españoles crecieron casi el 20\%, deudas en su mayoría desti- 


\section{Ignacio Cervera Conte}

nadas a la adquisición de la vivienda. La carga financiera asociada a dichas deudas alcanzó el valor más alto de los últimos años y todo el ahorro estaba prácticamente destinado al servicio de la deuda (p.151). Y aunque señalaba la preocupación por este endeudamiento, se confiaba en los márgenes de las entidades bancarias para absorber el impacto de una eventual materialización de algunos de los riesgos asociados al mercado inmobiliario.

En el Informe Anual 2005 se recoge una desaceleración de la revalorización de la vivienda. Pero los precios siguen subiendo, esta vez, al 13\%. Esta menor revalorización de la vivienda hizo pensar en un escenario de "absorción ordenada de la sobrevaloración actual del mercado inmobiliario."

El aumento de la riqueza de los hogares españoles se debió principalmente a esta revalorización. Aún así, el regulador vuelve a avisar:

"A pesar del crecimiento del patrimonio de los hogares, el aumento del endeudamiento y de la carga financiera junto con la reducción del colchón de ahorro disponible para hacer frente a perturbaciones adversas sin ajustar a la baja su nivel de gasto han elevado nuevamente su exposición a variaciones desfavorables en su renta, en el precio de los activos y en el coste de financiación" (p. 173).

No obstante, el banco regulador seguía confiando en la capacidad de las entidades bancarias para afrontar la materialización de los riesgos asociados al mercado inmobiliario.

El Informe Anual 2006 ya se hace eco de una desaceleración en la revalorización de activos inmobiliarios, que fue del 9,1\%, pero para ese momento el endeudamiento de las familias y las cargas financieras asociadas a ese endeudamiento son realmente altos. Hasta este momento, en ninguno de los Informes Anuales ha aparecido la palabra "burbuja", excepto para hablar de burbujas financieras de otros países.

Se puede concluir que el Banco de España se limitó a constatar en sus informes:

a) Que a pesar de la dificultad de contar con un precio de equilibrio que sirviera de referencia, existía una clara sobrevaloración de los activos inmobiliarios que no estaba justificada por datos coyunturales ni por los análisis fundamentales.

b) Que esa sobrevaloración coexistía con un enorme endeudamiento de los hogares españoles, de las sociedades inmobiliarias y de las constructoras con altas tasas de crecimiento anual.

c) Que los hogares españoles, junto con el endeudamiento, veían aumentar el valor de su riqueza gracias a la subida de los precios de los inmuebles.

d) Que la exposición al riesgo de una subida de los tipos de interés o de una caída de los precios era real y preocupante. 
5) Que los inmuebles no sólo eran bienes para los nuevos hogares sino activos financieros atractivos para inversores.

Estas advertencias del Banco de España se han encontrado siempre con la fuerte oposición de quienes estaban interesados en que los precios de los activos inmobiliarios subieran indefinidamente. Muchos apelaban a la inexistencia de tal burbuja inmobiliaria y se describía el fenómeno inmobiliario como un mero ciclo alcista. De hecho, estas advertencias no fueron atendidas. ¿Por qué no fueron atendidas estas advertencias del Banco de España?

\subsection{Un círculo vicioso e interesado.}

Para poder responder a esta pregunta, antes hay que exponer el procedimiento de concesión de un crédito hipotecario en España: Un cliente que quiere adquirir una vivienda acude a una entidad financiera para solicitar un crédito hipotecario. El Banco de España recomienda que el importe del crédito no supere el 80\% del valor de la vivienda. Antes de otorgar el crédito, el banco acude a una agencia de tasación para valorar la vivienda que su cliente quiere adquirir. Si el cliente no puede pagar el 20\% de la entrada de la operación, el banco deniega el crédito a su cliente. Sin embargo, como bien señala García Montalvo (2009), hay una estratagema que puede obviar este contratiempo: si la agencia tasadora aumenta el valor de la vivienda, el cliente puede llegar a conseguir un crédito de hasta el $100 \%$ del valor de la vivienda. Esta estratagema es factible si tenemos en cuenta que, por un lado, más de la mitad de las agencias de tasación están participadas por los bancos; por el otro, los directores de sucursales bancarias, con una gran discrecionalidad entonces en las decisiones de concesión de créditos, han recibido una compensación variable en función del volumen de hipotecas que vendían.

Por consiguiente, todos los participantes en este procedimiento tienen sus intereses alineados, si bien, este alineamiento, como enseña la experiencia, no incluye el interés general. Este sistema de financiación se auto-reforzó con la creación continua y cada vez más acelerada de nuevos créditos hipotecarios bajo la ilusión de unos precios, como los precios de los inmuebles, que nunca bajarían (especialmente si estaban interesadamente sobrevalorados con la ayuda de agencias tasadoras). Los créditos concedidos por las entidades financieras fueron concentrándose cada vez más en la financiación inmobiliaria. Los bajos tipos de interés y el exceso de liquidez ayudaron a esta concentración. Pero cuando los tipos de interés comienzan a subir y los precios de la vivienda empiezan a moderarse, el proceso se invierte dramáticamente:

"los compradores de vivienda dejan de pagar las hipotecas; los bancos dejan de estar interesados en originar nuevos créditos; se acumulan viviendas embargadas 
que se venden a precios de saldo, provocando una caída superior de los precios:

El sistema comienza a funcionar en reversa" (García Montalvo 2009).

Es decir, se vuelve a incurrir en el desarrollo de un sistema financiero que se aleja de su objetivo, que es financiar actividades productivas sostenibles en el tiempo.

\section{HACIA UN OBSERVATORIO DE LAS BURBUJAS FINANCIERAS.}

Ya se ha hecho referencia a los perjuicios que provoca sobre la economía de un país o región, el alejamiento del sistema financiero de su finalidad que es el servicio a la economía real. Una lección fundamental que se debería sacar de esta crisis es la prevención de futuras burbujas. Pero ¿cómo prevenir futuros episodios especulativos donde los precios de mercado no se correspondan con los valores fundamentales de los activos?

Hay que reconocer que no es fácil, y que las burbujas se advierten con certeza cuando ya se está inmerso en una de ellas. A veces cuesta distinguir entre la creación de una burbuja y un desequilibrio temporal de los precios de mercado. La diferencia entre el precio de mercado y el valor fundamental podría ser un primer indicador; pero ¿qué tamaño debe adoptar esta diferencia para que indique que se está ante una burbuja y no ante un desequilibrio? La persistencia de esas anomalías del mercado en el tiempo podría ser otra indicación; pero ¿dónde se pone el límite temporal que distinga entre una burbuja y un desequilibrio en el tiempo? Por otro lado, cuando se tiene la certeza de que se está en una burbuja financiera, ¿cómo hacerla estallar sin que produzca daños?

En cualquier caso, la prevención debería de ser el primer objetivo para evitar futuras burbujas. En junio de 2013 el gobierno español ha anunciado la creación de un consejo liderado por el Banco de España e integrado por la CNMV y varios ministerios, con el objetivo de prevenir los riesgos sistémicos producidos por un excesivo endeudamiento de hogares, empresas y administraciones públicas que condujeron al estallido de la burbuja inmobiliaria. Desde aquí hay que celebrar la creación de este consejo, aunque también hay que recordar que en España ya existe desde 2005 el CESFI, un comité de estabilidad financiera integrado por los ministerios de Economía y Hacienda, el Banco de España, la CNMV y la Dirección de Seguros y que tiene como objetivo, entre otros, la prevención de crisis financieras. Viendo lo que ha ocurrido desde entonces no parece que el CESFI haya sido muy efectivo. Cabe preguntarse qué diferencia hay entre la comisión creada por el gobierno y el CESFI y por qué este último no ha evitado la burbuja inmobiliaria.

Este comité debería tomar en consideración algunas medidas preventivas que se han propuesto para evitar el alejamiento del sistema financiero de su finalidad. 
Las presentamos a continuación.

\subsection{Créditos debidamente orientados a la productividad sostenible.}

Ya se ha expuesto con suficiente detalle que la apelación al crédito está muy presente en el origen de todas las burbujas analizadas. Sin embargo, toda empresa y toda economía necesitan acudir al crédito para crecer y desarrollarse de forma sostenible. Luego no todo el crédito contribuye a la creación de una burbuja.

Werner (2012) distingue entre créditos enfocados a la creación de riqueza nacional (créditos productivos) de los créditos que son para meras transacciones financieras (créditos no productivos). El incremento de estos últimos créditos crea alzas insostenibles de los precios de los activos seguidas de crisis bancarias.

Convencido de que las economías que orientan sus créditos hacia un uso productivo y sostenible del mismo tienen más probabilidad de alcanzar un desarrollo económico superior acompañado de un sistema financiero estable, Werner (2012) propone la creación de una "orientación del crédito" (credit guidance) llevada a cabo por los bancos centrales de cada país o zona económica.

Para ello, Werner (2012) propone como señal anticipatoria del comienzo de una burbuja, la ratio

Crédito para transacciones financieras

\section{Crédito total}

que acompaña a la comparación del crecimiento del crédito total con el crecimiento del PIB nominal. Ante un incremento de la proporción del crédito para transacciones financieras sobre el crédito total, hay que comparar el crecimiento del crédito total con el crecimiento del PIB nominal: un crecimiento del crédito total más rápido en el tiempo que el crecimiento del PIB nominal, sólo puede venir por el crecimiento del crédito para transacciones financieras, y por consiguiente, apunta a una expansión excesiva e insostenible del crédito.

La misma publicación The Economist ${ }^{2}$ apoya este predictor de burbujas financieras cuando postula que existe una expansión excesiva del crédito cuando "la diferencia entre la tasa de crecimiento del crédito bancario y la tasa del crecimiento del PIB nominal" se amplía en el tiempo.

Un observatorio de las burbujas financieras debería ayudar al regulador (en este caso a los bancos centrales) a evitar la proliferación de créditos dirigidos a operaciones financieras que no crean riqueza real.

\footnotetext{
2 "Some like it hot, Which emerging markets are at the great risk of overheating?", 2 de Julio de 2011, p.69.
} 


\subsection{Precios de mercado de acuerdo a valores fundamentales.}

Uno de los componentes de las burbujas financieras es el alejamiento de los precios de mercado de los valores extraídos de un análisis fundamental. Ya se ha indicado que la valoración de una acción de una compañía a través del análisis fundamental está basada en toda la información pública disponible y en las expectativas que se tengan acerca de los futuros beneficios de dicha compañía. El mercado asigna un precio a dicha acción basado también en esas expectativas. Sin embargo, puede ocurrir que el valor fundamental no coincida con el precio, como ocurrió en muchas compañías en los momentos previos al estallido de la crisis.

Tal fue el caso de Astroc Mediterráneo, una empresa inmobiliaria valenciana que salió a Bolsa en mayo de 2006 a 6,4 euros por acción, y comenzó una fulgurante revalorización que la llevó a multiplicar por más de 11 veces su valor hasta tocar un precio de cierre máximo de 72,6 euros por acción en febrero de 2007, es decir, en nueve meses. Desde esa fecha, la inmobiliaria comenzó una no menos espectacular caída en su cotización que le llevó a situarse con un precio de cierre de 5 euros por acción al final del año 2007. En febrero del 2008 se crea un grupo inmobiliario, Afirma Grupo Inmobiliario, que se hace cargo de Astroc Mediterráneo cuando ya obtenía el 31 de enero un precio de cierre de 2,69 euros la acción.

Con el precio objetivo, los analistas financieros formulan la cotización que debería alcanzar una empresa dentro de los doce meses siguientes. Este precio objetivo se obtiene a través del análisis fundamental, es decir, a través de la información pública disponible y de las expectativas futuras sobre los beneficios de la empresa analizada. En base a este precio objetivo determinan si un activo financiero está sobrevalorado o infravalorado, y a partir de esta estimación formulan su recomendación de compra o de venta. Llama la atención que el consenso de los analistas financieros fijaba el precio objetivo de la acción de Astroc Mediterráneo en un margen de 5,5 a 7,1 euros la acción ${ }^{3}$ para ese periodo en que se produjo el aumento de su cotización (mayo 2006 a febrero 2007). Es decir, el consenso de los analistas ya avisaba de una sobrevaloración desproporcionada de la acción de Astroc Mediterráneo.

Los reguladores, tanto el Banco de España como la CNMV, deberían de poder contar con un consenso realizado por analistas financieros independientes (es decir, analistas no contratados por bancos o por cualquier otra entidad financiera) que, al compararlo con las cotizaciones, les permita avisar a los inversores en general cuándo el precio es desorbitado y que, por consiguiente, cuándo se encuentran ante una burbuja financiera que puede estallar en cualquier momento.

\footnotetext{
${ }^{3}$ El consenso de los analistas es representada por la mediana de los precios objetivos otorgados por analistas financieros para Astroc Mediterráneo que recoge la empresa de datos financieros I/B/E/S.
} 


\subsection{Un modelo de financiación inmobiliaria creíble y sostenible.}

Ya se ha visto el círculo interesado que ha alimentado la burbuja inmobiliaria en España: el cliente que quiere una nueva vivienda y acude al crédito hipotecario; el banco que tiene incentivos en concederlo; finalmente, la agencia tasadora (ligada a un banco) dispuesta a tasar la vivienda a un precio que interese a todos. García Montalvo (2009) propone una solución al modelo de financiación inmobiliaria: que la limitación que el Banco de España recomienda en la concesión de créditos hipotecarios se corrija: en lugar de conceder un crédito hipotecario por un máximo del $80 \%$ del valor tasado de la vivienda, se conceda por un máximo del $80 \%$ del valor registral. Es decir, cambiar el valor tasado por el valor registral. Este cambio rompería este círculo vicioso e interesado ya que aumentar el valor registral de la vivienda para conseguir un crédito por un importe mayor desincentiva al cliente porque tendría que soportar una mayor carga impositiva.

Otros como Burón (2011) han propuesto no permitir créditos que supongan dedicar más de un 30\% de los ingresos mensuales ordinarios de una persona o familia al pago de la hipoteca.

Posiblemente ninguna de las medidas evite totalmente la aparición de nuevas burbujas, pero al menos dificultarían su aparición.

\section{CONCLUSIÓN: NO PERDER LA MEMORIA FINANCIERA Y PREVENIR.}

En el comienzo de este artículo se ha señalado la importancia de los sistemas financieros, como instrumentos que canalizan los ahorros de muchos hacia las inversiones productivas que contribuyen al desarrollo económico de un país o de una zona geográfica. Cuando un sistema financiero se olvida de que es un instrumento al servicio de la economía real, el mecanismo de la asignación de precios de los mercados se vuelve errático. Las burbujas son la evidencia más clara de que el mercado no está asignando correctamente los precios de los activos, más bien los está sobrevalorando. Se ha escrito mucho (y se escribirá aún) sobre las burbujas financieras. Las burbujas han tenido lugar en casi todos los activos que se negocian en los mercados internacionales.

No suele haber una sola causa en sus comienzos y suelen coincidir una serie de factores en su eclosión: Un contexto de los tipos de interés extremadamente bajos que estimulan el excesivo recurso a los préstamos para ser invertidos en un activo, con la creencia de que su precio va a subir siempre. Todo ello bajo la ilusión de que existe una máquina inagotable de hacer dinero. El sistema financiero se olvida así de su función y contribuye a que este mecanismo de la burbuja se autoalimente hasta que la misma estalla. 
Cuando estalla la burbuja, muchos experimentan una fuerte pérdida de valor de los activos en los que invirtieron, llegando incluso a la quiebra. Aunque no es fácil saber si se está ante una burbuja en su fase inicial o ante un desequilibrio temporal de los precios, por el bien de una economía que crece sosteniblemente hay que buscar todos los mecanismos que impidan su creación. Aquí se han recogido algunas propuestas. Con ello se contribuye a que el sistema financiero cump la su vocación de servicio a la economía real.

\section{BIBLIOGRAFÍA.}

BANCO DE ESPAÑA, Informe Anual 2001, Madrid 2002. , Informe Anual 2002, Madrid 2003. , Informe Anual 2003, Madrid 2004. , Informe Anual 2004, Madrid 2005. , Informe Anual 2005, Madrid 2006. , Informe Anual 2006, Madrid 2007.

BURÓN, J. (2011), "Evitar la burbuja inmobiliaria”, Cinco Días 10/02/2011. CAUWELS, P. y SORNETTE, D. (2012), "The Illusion of the Perpetual Money Machine" Notenstein White Paper Series. Disponible en: http://arxiv. org/ftp/arxiv/papers/1212/1212.2833.pdf (consulta: 15 de Junio de 2013).

GALBRAITH, J.K. (1994), A short history of financial euphoria. Penguin Books USA

GARCÍA MONTALVO, J. (2009), "Financiación Inmobiliaria, Burbuja Crediticia y Crisis Financiera: Lecciones a partir de la recesión de 2008-09", Papeles de Economía Española, núm. 122, pp. 66-85.

GIMENO, R. Y MARTÍNEZ-CARRASCAL, C. (2010), "The relationship between house prices and house purchase loans: The Spanish case", Journal of Banking \& Finance, núm. 34, pp. 1849-1855.

SÁNCHEZ ASIAIN, J. Á. (1987), "El progresivo divorcio entre el mundo real y el mundo financiero", en Anales de la Real Academia de Ciencias Políticas y Morales, Sesiones de los días 3 y 10 de noviembre de 1987. Disponible en: http://www.racmyp.es/docs/anales/A65/A65-6.pdf (consulta: 10 de Septiembre de 2013).

THE ECONOMIST (2011), "Some like it hot, Which emerging markets are at the great risk of overheating?", The Economist, UK Edition, 2 Julio 2011, p.69

WERNER, R.A. (2012), "Towards a new research programme on 'banking and the economy'. Implications of the Quantity Theory of Credit for the prevention and resolution of banking and debt crises", International Review of Financial Analysis, núm. 25, pp. 1-17. 